\title{
Board 8: Engineering Management Division: Implementing Lean Practices in an Academic Department: A Case Study
}

\section{Prof. Byron G. Garry, South Dakota State University}

BYRON GARRY is Associate Professor and Undergraduate Program Coordinator in the Department of Construction \& Operations Management in the Jerome J. Lohr College of Engineering at South Dakota State University. He has been a member of ASEE since 1998. As SDSU ASEE Campus Rep., his goal is to help fellow College of Engineering faculty to be reflective teachers. 


\section{Implementing Lean Practices in an Academic Department: A Case Study}

\section{Dr. Ekaterina Koromyslova, South Dakota State University}

Ekaterina Koromyslova is an Assistant Professor in the Department of Construction \& Operations Management in the Jerome J. Lohr College of Engineering at South Dakota State University.

\section{Dr. Carrie Steinlicht, South Dakota State University}

Dr. Carrie Steinlicht is an Senior Lecturer of Operations Management. She teaches several courses including courses on Lean Practice in Operations Management. She has several years of industry experience as an advanced development engineer and has served as a consultant to industry for over 10 years.

\section{Dr. Teresa J.K. Hall, South Dakota State University}

Hall is currently professor and head of the Construction and Operations Management department at South Dakota State University. She also serves the JJ Lohr College of Engineering as program coordinator for the professional masters degree in Engineering.

\section{Dr. Albena Yuliyanova Yordanova, South Dakota State Univeristy}

Education: University of Northern Iowa, Cedar Falls, Iowa; Doctor of Technology with emphasis in Sustainable Design \& Construction (2016); University of Missouri, Columbia, Missouri ; Master of Arts in Architectural Studies (2005); Institute of Architecture and Civil Engineering, Sofia, Bulgaria; Professional Diploma in Architecture (1991). Currently teaching at South Dakota State University, Construction Management Program (2010-present). Area of interests: Sustainable Building Design and Construction Materials. Professional experience: Architecture in the U.S.A., and Bulgaria, the E.U.

\section{Prof. Byron G. Garry, South Dakota State University}

BYRON GARRY is Associate Professor and Undergraduate Program Coordinator in the Department of Construction \& Operations Management in the Jerome J. Lohr College of Engineering at South Dakota State University. He has been a member of ASEE since 1998. As SDSU ASEE Campus Rep., his goal is to help fellow College of Engineering faculty to be reflective teachers. 


\title{
Implementing Lean Practices in an Academic Department: A Case Study
}

\begin{abstract}
Lean approaches to continuous improvement, originally practiced and perfected by Toyota Motor Company, have been widely used in the industry sector for many decades. There is a growing trend at universities to adopt lean practices to improve higher education processes. Reduced financial support and growing competition amongst universities and academic programs motivate the implementation of lean practices both at university and department levels. ${ }^{1}$ Colleges and universities that have adopted lean practices are driven by the need to strategically leverage resources to meet stakeholder expectations, reduce waste or costs, and improve satisfaction with under-performing processes. ${ }^{2}$ This paper presents an overview of the continuous improvement journey at the Construction \& Operations Management (COM) Department at South Dakota State University (SDSU) and demonstrates proof of concept via a case study which describes a Kaizen event performed in a multi-disciplinary academic department, in a college of engineering. Higher education is a labor-intensive process, and the department seeks to eliminate non-value added activities of faculty and staff, reduce time and effort required in daily processes, and to improve student learning experiences in the department. These all illustrate important concepts that engineering management education delivers to students. The approach, challenges, and outcomes are presented in the paper to inform best practices in lean higher education.
\end{abstract}

Keywords Lean in Higher Education, Continuous Improvement, 5S, Kaizen

\section{Introduction}

The financial crisis of 2008 and dwindling financial support for higher education triggered the investigation of new methods to stay competitive and efficient among the higher education institutions (HEI). American universities are faced with a competitive challenge where simply raising tuition to fill the gap in revenue is counterproductive in attracting students.

Benchmarking from industry and the concept that higher education processes are similar to manufacturing processes ${ }^{3}$ led to adopting Lean methodology by HEI to reduce waste, streamline processes $^{4}$, and to address the economic pressure ${ }^{5}$. While the lean approach to management is still emerging in the university settings, American, Canadian, and British universities are the most committed to its implementation. Nevertheless, Saudi Arabian, African, and Asian universities are also adopting lean principles in their practice ${ }^{6}$.

Both newly developed and established administrative processes are potential opportunities for improvements ${ }^{7}$. Most projects focus on operations such as financial transactions, facilities management, human resources and library services. Based on documented results by early adopters in higher education, clear continuous improvement is part and parcel of organizational strategic planning and applied within daily operations at forward-thinking institutions. ${ }^{2}$

Improvements from lean in higher education include reduction of waiting time for student services, decreasing response time on prospective student's requests, eliminating unnecessary steps in administrative processes, and reducing backlogged repair of campus facilities. ${ }^{2}$ Financial improvements include cost avoidance, cost reduction, and increased revenue. ${ }^{8}$ 
The Construction and Operations Management (COM) department of the South Dakota State University (SDSU) offers courses where students learn the use of lean processes in such areas as supply chains, manufacturing processes, and cost analysis. The COM department realized that improvements were needed in some of their own processes. The goal of this paper is to demonstrate another facet of lean management practices in higher education - improvement of processes to reduce non-value added time of faculty members and staff. The authors aimed to contribute to the Lean Higher Education best practices by presenting the case study completed within the South Dakota State University Lean initiative.

\section{Lean Practices in Higher Education Institutions (HEI)}

Since Lean became a management philosophy in Higher Education, the approach has been considered as a method of reducing costs and increasing the quality of education ${ }^{9}$. In comparison with manufacturing Lean practices, the concept is still quite new for Higher Education, and it has not been introduced to universities as a whole but more commonly in discrete systems or processes $^{6}$. Most popular projects for Lean improvements were related to the support and administrative processes ${ }^{5}$. According to Nadeau ${ }^{6}$, the major barriers to enhance the Lean methodology in academia are the correct determination of added value, different types of waste, and defining a client of the process improvements. Kang and Manyonge ${ }^{10}$ in their study defined the types of waste which can be found in HEI with focus on the waste of over-processing and excessive motion. They considered three basic categories for process improvement: Students, Research, and Staff, and included the teaching assessment and research life cycle processes in the list of processes for improvement using Lean tools. The authors described a $5 \mathrm{~S}$ project for processing and storing of students information which resulted in reduced waiting time and better quality of service for students.

In attempt to determine the ways for adoption of Lean methodology and to define the major components such as value stream, customer, and waste, the researchers analyzed the relationship between lean philosophy and engineering education which is focused on teaching these Lean principles $^{5}$. Jahan \& Doggett ${ }^{11}$ in their study investigated perception of undergraduate students at a higher education institution. They collected students' responses over two years as the assignments in the Lean Manufacturing class, asking how to apply lean principles to the higher education settings. Key findings from their responses were that students defined an employer of future graduates as a customer of the education process. All their recommendations were related to the improvement of teaching and student service processes. Although an employer was named as a first customer, students' recommendations on curriculum improvement, campus layout, and facilities utilization demonstrated that students considered themselves as customers as well. Francis ${ }^{4}$ in his study of lean implementation in Canadian universities pointed out strong prospects for new research programs related to Lean in higher education. The universities potential in producing rigorous research should be leveraged to promote the lean adoption as a system in HEI.

Although some authors believe that in the recent years it has become easier to use Lean methodology for non-experts in the field ${ }^{9}$, most of the studies highlight the importance of personnel training and expert's mentoring of Lean management processes, ${ }^{4,7}$ especially in collaboration with lean experts from industry ${ }^{12}$. For instance, other tools and methodologies of continuous improvement such as DMAIC, lean, six sigma, and lean six sigma were enumerated 
and encountered in higher education. Lack of appropriate training and practice in use of these methods could be challenging. Thus, Mazumder ${ }^{3}$ proposed to use the Six Sigma DMAIC methodology to improve quality of an engineering education process. The author considered the education process, from students' admission in a program until graduation, as a transformation process similar to one in manufacturing. Mazumder ${ }^{3}$ named the factors, which influence the quality of education, proposed a way to quantify those factors along with measures of outcomes, and demonstrated how statistical process control, cause-and-effect analysis, and the Failure Mode and Effect Analysis (FMEA) can be used with the Six Sigma process in Higher Education.

Bargerstock \& Richards ${ }^{13}$ studied the DMAIC methodology in application to the academic assessment process. They defined faculty as one of the customers and determined wastes associated with data collection for assessment and administrative reporting. Among the other wastes, they named multiple forms of duplication, summarizing data from various different sources, and waiting for all required documents to become available for analysis. A close-theloop (CTL) approach was used in this Kaizen project. Outcomes included improved faculty morale, reduced frustration with assessment reporting, and decreased time for the report preparation.

Svensson, Antony, Ba-Essa, Bakhsh, \& Albliwi ${ }^{14}$ in their paper highlighted challenges of implementation of Lean Six Sigma methodology in a university in Saudi Arabia, which targeted its administrative processes for improvement. One of major challenges the university faced was the fact that not all improvements can be initiated due to strict regulations from the Saudi Arabian government. Thus, it can limit the freedom of the HEIs to develop their own policies and regulations of administrative processes. Waterbury ${ }^{15}$ in her research highlighted the importance to understand the role of the senior leadership team when implementing Lean as a continuous improvement strategy. Reilly, Healy, Murphy, \& O’Dubhghaill ${ }^{16}$ defined key readiness factors which play role of "a pre-requisite to the successful implementation, deployment and sustainability of LSS in HEIs". These factors are "leadership and vision; management commitment and resources; linking Lean Six Sigma to University strategy; customer focus; and selecting the right people" (p.8). Although these findings are based on results from Irish universities, the named factors commonly take place in American higher education institutions.

The leading researchers in the Lean Higher Education (LHE) movement pointed out that the process of implementation of Lean methodology in universities is still limited to a small number of cases and to a few measured results ${ }^{2}$. Nevertheless, there are several Universities committed to adopting Lean at all levels of a value stream, and which have achieved significant results in terms of cost savings, improved productivity, and satisfaction of all stakeholders. ${ }^{7,17}$ A notable outcome of the universities' lean initiatives is the dissemination of their approaches and achieved results to the broad audience and to their employees via organized meetings, newsletters, and recognitions of faculty and staff.

\section{Background of Launching the Lean Initiative at the South Dakota State University}

Continuous improvement is one of the important components of the South Dakota State University strategic planning aimed to advance the land grant mission in teaching, research, and outreach. Three major areas have been identified as a focus for continuous improvement: utility infrastructure, application of technologies to reduce paper-based processes, and overall processes 
improvement utilizing the Lean framework. SDSU began its Lean journey in 2013 with the first projects of improvement of Library space utilization and Print Lab processes. A Lean Processes Task Force was formed to address the goal to grow the SDSU's capacity as a high-functioning university via the integration of Lean management practices. In 2015 the SDSU created the Office of Continuous Improvement (OCI) with three main responsibilities: training employees on Lean concepts, facilitating process improvement projects, and outreach. The Director of Continuous Improvement (CI) has trained over 250 employees. A Lean Champions program has been launched with the goal to prepare departments-Lean Champions to lead Lean efforts across the university.

With the continuous support from the top management, which is vital for successful Lean management practices ${ }^{8}$, the Lean initiative has been growing at the South Dakota State University. Two recent projects facilitated by the Director of CI were the Graduate Admissions Process for the College of Nursing to make the process more effective and efficient for applicants and faculty, and a key First Year Advising Center process to reduce the amount of workload dedicated to administrative tasks and allow more time to advise students. Noticeable outcomes for the first project were standardized documentation and timing for admission cycles which resulted in reducing the admission cycle from three weeks to one week, and reducing the admissions review committee meetings from six hours to two meetings at less than one hour each. The First Year Advising Center process has been improved by eliminated steps in the advising process that did not add value for the student and by empowering advisors to make work process decisions which resulted in increased amount of time available to meet with students.

As part of the SDSU continuous improvement efforts, the Construction and Operations Management Department assigned one of its faculty members the task of leading targeted improvement projects aimed at making department processes more efficient and effective. This faculty member had been involved in facilitating other improvement efforts across campus and is the primary instructor for lean courses in the department.

\section{A Case Study: Lean Initiative in the COM Department}

Over the summer of 2017, the COM department head and the facilitator reviewed a list of potential projects and proposed 3 potential projects to undertake by faculty and staff members. Best practice indicates that improvement initiatives are much more successful when the initial project is a quick win. Researchers have demonstrated that selection of the first project is instrumental in further engagement of participants. Choosing a project that is unlikely to fail and highlights the improvement processes ability to provide meaningful results is instrumental to sustaining continuous improvement ${ }^{13}$. The 3 projects proposed by the COM department were designed to address major discomfort points in the department. Faculty and staff had, in the past, expressed frustration with each of the proposed projects. The faculty and staff reviewed the list of projects and ranked them according their personal preferences.

\section{S Project: Housekeeping of the Shared Electronic File Storage Area}

The first project chosen for improvement was the electronic file storage area used by the COM department which served as a good project for introducing the department members to lean thinking and the improvement process. This project was essentially a $5 \mathrm{~S}$ project with the goal of 
organizing stored documents and data such that faculty and staff would reduce wasted time finding a document or file they needed when they needed it.

Faculty and staff were introduced to lean by providing them with a book with a lean introductory section that describes the basic lean principles and introduced the concepts of the 7 wastes. Faculty and staff were asked to read the section of the book and then go into the shared electronic storage location, or shared drive, and find 3 specific documents. As they looked for the 3 documents, they were asked to document the amount of time it took for them to find the files.

This type of preparatory work is common in at the start of a kaizen as these events typically are completed in short bursts of time. To facilitate a focus on improvement, document collection and examination of current methods and procedures may start ahead of the actual event. This serves as means to effectively map the current process prior to developing an ideal future state.

At the initial meeting, faculty and staff were asked to share how much time it took for them to find the files. Some of the files were easy to find and some were very difficult. After discussion, faculty and staff noted that those files that they had found easily were those they regularly had to use or they had put the file in themselves. Some reported taking as much as 15 minutes to find files and some reported giving up on finding some of the files. After noting the varied methods people used to find documents, it was apparent to all that improvement was necessary. Measuring a baseline for a project to compare with the values after improvement is an essential part of Lean methodology ${ }^{2}$.

The next step was to define the project scope and objectives. The group spent a little time building and refining a project statement that described exactly what the project was, what its boundaries were, and the objective that would be achieved at the end of the project. The project statement was: "Developing/Creating a structure and process of organizing the files in the department shared drive files to improve search capabilities, version control and storage protocols." Ideally, the group wanted to be able to log in to the shared drive, see the correct folder, open the appropriate sub-folder, and then access the correct file, with little or no backtracking.

Once the group was comfortable with the definition of the project, the group decided to improve the organization of the folders. The first discussion was to determine what files should be allowed to be in the shared drive. Some faculty had, in the past used the drive to backup their personal computer drive or had posted large files that took up significant space. There were also multiple files containing outdated forms and procedures. All these items had an impact on the limited shared drive space assigned to the department.

After discussion, the group decided that the shared drive was only for files that everyone in a program or department might need to access. Forms that can be found on the university website should not be found on the shared drive. Commonly used forms that are difficult to find may be found in the shared drive, but, only as a link to the university website. Once this was decided, the group developed a list of folders that should be found on the first page of the shared drive. Each program was given a folder for program specific files. Files shared across the department went into department folders. A folder was added for files from the College which does not have a file location but is shared with the department. Each program and the department was given an archive folder for old documents that may still need to be accessed and another file was added for Orphan documents; documents that need a location, or, the person filing it does not know 
where it should be placed. This folder would be cleared after the shared drive is cleaned up and organized. The final file added was a search index that showed sub-folder locations without having to open multiple folders.

The second discussion point was how to name the files so that it was easy to determine the file content and the relevance of the document. A universal file naming convention was defined that everyone was encouraged to use for their personal files as well. All files are to be named by starting with the program identifier. All the program and department acronyms that could be used were defined. The second part of the file name shows the content of the file. If the file is a form, the word form must be used in the name of the file. The third part of the file name is the date for the file. If the file typically changes only once a semester, such as a syllabus, the file date would start with the semester prefix, then the last two numbers of the year. If the file is not associated with a semester, then the file date would be structured with the month, day, and year (MM-DD-YY).

The last thing the group discussed was the rules for storing documents. The group decided that files will always be stored in the appropriate folder. There will be no duplicate files allowed. New folders may only be added by agreement of all the faculty and staff of the department (for the root drive) or the program (for sub-folders). All added folders will be noted in the search index by the person adding the folders. Course related files will always be located according to prefix, not program.

After determining the folders, locations, rules and procedures, the group assigned tasks for cleanup and moving files to several members of the faculty and staff. A deadline for completing the cleanup was set by the group, and the meeting adjourned.

At the next faculty and staff meeting, the file system was reviewed. Some minor changes were suggested to improve the shared drive system and a couple of omissions were corrected. An example is that there is a discontinued program that has documents and student information that must be maintained for a period of time according to university policies. Another improvement was that example file names were added to the file naming rules to clarify how files should be named. In addition, orphan files were reviewed and categorized by the group.

Faculty and staff were pleased with the results and reported a significant decrease in time (less than one minute in comparison with 10-15 minutes before the $5 \mathrm{~S}$ project) to find files.

\section{Kaizen Practice: Student Advising Process}

To sustain the momentum we had established on continuous improvement, a second improvement event was scheduled after the end of the first project. Prior to starting this project, the facilitator wrote a documented department process improvement procedure. This is based upon the practice of kaizen, or incremental improvement, used in lean initiatives.

1. Pick one process to improve

2. Define scope

3. Map process

4. Verify map

5. ID opportunities for improvement

6. Choose opportunities for examination 
7. Form a team(s) to examine individual opportunity(s) and propose new methods or improvements

8. Team tests methods and develops recommendations

9. Team presents recommendations to department and facilitates discussion

10. Implement consensus recommendation

11. Standardize method

12. Document/Map method

The same group of faculty tackled the second most popular choice of projects from the original survey. This project was selected to improve the student progression processes performed by the faculty and staff in the COM department. This project would address another problem that was frequently brought up at faculty and staff meetings. The current student advising and tracking process was confusing, cumbersome, and opaque to many in the department. The group was anxious to come up with better methods for monitoring student progression to degree completion.

The group started as before with a definition of the project. The group determined that the scope of the project would include all process steps from the time the student initially has contact with the department until they graduate. The stakeholders for this project were the department administration, faculty, staff, current students, and prospective students with whom the program check sheet was shared.

The next step was to map the steps of the process. This stage of the improvement process took a couple of meetings over a period of about 3 weeks. When the group was done it had identified around 100 process steps and had identified 12 distinct opportunities for improvement based upon "bursts" identified during the mapping process.

The process mapping exercise in this kaizen event revealed that each faculty member had a different process for advising students, that is, none of the faculty advised students in exactly the same manner. Participants expressed surprise at the differences in the approaches and some even said that the mapping process gave them some ideas on how to improve their methods. The faculty discussed the differences and decided that advising is an individual activity that benefits from varied approaches based upon the advisor and student. Standardizing this method would not enhance the student experience.

Once the mapping was complete, the group chose to work on one particular improvement opportunity that would address the greatest pain point in the entire progression process. This was the student program check sheet. Each department at the university maintains individual Excel check sheets for each student enrolled in its programs as the tracking tool from central computing is not reliable. These check sheets serve as a means to inform students of the required courses in their program and maps these courses to appropriate semesters. This check sheet is updated on a continual basis to reflect what courses are completed, what courses have prerequisites, the student's grades in the courses, the progress on university and state general education requirements, etc. The student, faculty, and department all use these check sheets as a basis for advising and planning. This document is not linked to the registrar's computing system and therefore cannot be automatically updated. Each document must be updated manually. There are over 300 students in the department and to update the document, one must access each individual student's records and transcripts. The COM department has just one staff member, 
who does not have the workload capacity to perform this task regularly. Therefore, the primary responsibility for updating these documents rests with the student's advisor. All the faculty members in the department have advising responsibilities.

This subproject was therefore, very important to all the faculty members. The goal for improving the check sheet was to make it easy to update and easy to read and use for student planning activities, however, still provide all the information needed for departmental planning processes. The most desirable way to enter data is to cut and paste all the data from the registrar's database into the spreadsheet. Doing this would simplify the process significantly. The faculty explored this possibility. Some of the faculty have extensive knowledge of databases and data management. These faculty noted that it would not be difficult to create an Excel spreadsheet macro that would automatically sort data pasted directly from the registrar's database. With this in mind, the faculty decided that the Excel workbook should have a location into which data can be pasted and sorted. Another suggestion was that data entry be on a separate worksheet from planning worksheets. This idea was extended to include worksheets for the department separate from student course selection and advising worksheets. Each worksheet could be configured to make it easy to find the necessary data for each function.

The group started by making a list of the pieces of information necessary for current and prospective students, the faculty advisor, and the department. The pieces of data were categorized according to which stakeholder would need that particular information. The list of information was examined and methods for ease of use were discussed. By the end of the discussion, several ideas were generated about the best data configuration for each function.

The facilitator asked the group members to come up with sample Excel worksheets that addressed the ease of use for each stakeholder and the meeting adjourned for a couple of weeks. At the next meeting of the group, several different worksheet designs were reviewed. Ideas were combined and modified until the group was reasonably happy with the design. One academic program was selected to test spreadsheet to determine clarity, visual appeal, and ease of use.

One of the faculty members volunteered to bring the spreadsheet into a class of senior level students and allow them to critique it. In addition, a few new students transferring to the program were allowed to choose which design they would like to use for monitoring their progression. The students overwhelmingly chose the new spreadsheet as a better, more visual tool. They agreed that the department should move forward to implement the new advising and tracking tool in place of the old worksheets we had been using.

Progress continues on this progression model at the time of this writing. Steps are being taken to develop similar spreadsheets for all other programs in the department. The department also intends to continue addressing the remaining issue bursts identified in the student progression map.

\section{Faculty Response}

The faculty who led the COM department through the lean processes had experience in the concepts and practice of lean from their educational background (advanced degrees in Industrial Education and Technology, and Organization and Management), teach courses in the Operations Management program of the department, and have led lean efforts for both businesses and other academic departments on campus. The other faculty in the department teach in the Construction 
Management and Electronics Engineering Technology programs in the department. They had heard some of the lean terms used before, but had no experience in implementing any lean processes. The general reaction was that the department's lean effort looked like it would take extra time and effort from the faculty, but they were willing to give it a try. Some of the faculty were asked to record their reactions to the process improvement journey.

The first request from the organizers was to ask faculty to read from "Lean Production Simplified" by Dennis ${ }^{18}$. Most faculty found this to be very informative, to see definitions for terms they had heard, but were unfamiliar with. One faculty said, "I appreciated finding out about the background of lean. The text attempted to simplify terms, and gave straight-forward examples, but trying to fit all the concepts together looks intimidating." Another faculty member said, "The reading was very insightful and has universal application in any organization."

For the first project, the 5S project to organize the department's stored documents, the organizers asked faculty to time themselves in finding three types of documents. One faculty member replied, "I found two of the files quite rapidly, as I produce, edit, and save those types of files in the shared drive quite often. But I could not find at all one of the department standard forms." Another faculty member said, "I did not know what a "5S project" was, as I missed the first meeting that introduced the concepts, so the second meeting was confusing." At the end of the $5 \mathrm{~S}$ project, now that a standardized file system was in place, all faculty across the COM department recognize that the effort invested was useful and will save them time and reduce frustration in the future when accessing shared drive files.

The second improvement process we undertook was the student progression model used by the COM department. All the department faculty recognized that they spend a lot of time, much of it feeling like wasted time, in tracking the information needed to advise students on their progression to graduation. After the success of the first lean project, there was enthusiasm about starting on the next project. That enthusiasm quickly ran into the difficult work of determining the current state, that is, figuring out what our individual current processes were. One of the faculty said, "I have access to one advising software programs that other faculty do not. I did not realize how much effort other faculty had to go through to pull together information from a variety of other software programs to get the same information." Another faculty member said, "This effort pointed out to me that I had not received any coordinated training when I started, to help me understand the advising process that the university and our department uses." Another common theme reported by the department faculty was surprise in seeing in total how staff, faculty, and administrative effort was invested in keeping the student's academic check sheets up-to-date, in order to advise the students properly. Seeing the duplication of effort, and the opportunities for improvement, encouraged the faulty to stay on task and do the hard work necessary to improve their processes.

At the time of this paper being written, the COM department has made some changes to processes, and is waiting to see how well those changes can be implemented. As a reflection of the journey so far, one of the faculty members said, "Some of the work done with all of the department faculty present might have been done more efficiently by small groups first, and then their thoughts shared with the entire department. Overall, I think the work that has been done will make our on-going advising efforts more efficient." A second faculty said, "The sessions on brainstorming ideas and finding out duplication of effort, as well as finding loopholes in 
organizing and keeping a system of file organization, were very helpful. We realized the need for clearly defined responsibilities and coordination between team members. I thought it would be useful after the $3^{\text {rd }}$ session to split into smaller groups (committees) to work on specific tasks, so that less time (in total) was spent." A faculty member admitted, "It has been difficult to write down what my current work process has been in many cases, because I do not always follow the same procedure. This work has opened my eyes to my own shortcomings in that area. Talking through these procedures gives me a push to be more deliberate in the advising work I do."

\section{Conclusion and Future Work}

The Construction and Operations Management department is committed to the South Dakota State University Lean Initiative launched in 2013. Besides participating in the campus-wide projects, the department members began practicing the lean methodology for its internal processes improvement. The approach and outcomes achieved can be viewed as a contribution to the best practices of Lean implementation in HEI. The department plans to preserve value-added activities, to make more efficient the required non-value added activities, and to eliminate unnecessary activities which do not add value to our stakeholders.

Admitting the fact that at the beginning of the lean exercise the department members perceived the participation as a coerced commitment, everybody was pleased with the gained outcomes from the activity. Use of a software was discussed as a possible solution within the $5 \mathrm{~S}$ shared drive housekeeping project, but it became clear that there was no need to introduce any kind of software for files management. The developed protocol and procedures for the shared drive file management system enabled the drastically shortened time for searching files. Clarity of file creating, storage, archiving, and deleting processes along with user's responsibilities, documented in the procedures, will contribute to sustainability of the improved system.

Regarding the Kaizen event, mapping of the current state of advising process revealed inefficiencies and room for improvement for each individual approach to students advising along with the overall process improvement needs. Working on the student progression model and the advising process improvement, the participants realized that not all bursts can be resolved at the department level, and changes are necessary at the college and university levels. Although the project is still in progress, the following outcomes are anticipated at its completion: reducing time for entering and updating the students' academic progress information, reducing the number of data entry errors, clarity of the program requirements and progression from entering the program and until graduation, a visual aid to support student's understanding of their program requirements, unification of the advising process, and more efficient utilization of faculty's time to advise students.

Faculty are engaged in the future work to address the identified bursts and to enjoy the results and benefits of the lean approach. The Construction and Operations Management department lean activity has been recognized at the university level, and the COM department is looking forward for more improvements with the appropriate support from all levels across the value stream. 


\section{References}

1. Balzer, W.K. (2010). Lean higher education: Increasing the value and performance of university. CRC Press: New York.

2. Balzer, W.K., Francis, D., Krehbiel, T. \& Shea, N. (2016). A review and perspective on Lean in higher education, Quality Assurance in Education, 24(4), 442-462.

3. Mazumder, Q. H. (2014). Applying six sigma in higher education quality improvement. Proceedings from 2014 ASEE Annual Conference \& Exposition, Indianapolis, IN.

4. Francis, D.E. (2014). Lean and the learning organization in higher education. Canadian Journal of Educational Administration and Policy, 157, 1-23.

5. Vukadinovic, S., Djapan, M., \& Macuzic, I. (2016). Education for lean \& lean for education: A literature review. International Journal for Quality Research, 11(1), 35-50.

6. Nadeau, S. (2017). Lean, six sigma and lean six sigma in higher education: A review of experiences around the world. American Journal of Industrial and Business Management, 7, 591-603. https://doi.org/10.4236/ajibm.2017.75044

7. Cristina, D. \& Felicia, S. (2012). Implementing Lean in a higher education university. Analele Universitatii Maritime Constanta, 13(18), 279-282.

8. Krehbiel, T.C., Ryan, A.W.Jr, \& Miller, D. P. (2015). Lean learning: University's challenges lead to \$27.2 million in cost improvements. Quality Progress, 48(2), 39-45.

9. Çalişkan, N., \& Mulgeci, A. (2015). Waste identification lean approach in effective education system - case of Albania. Academicus, 12, 199-206.

http://dx.doi.org.excelsior.sdstate.edu/10.7336/academicus.2015.12.14

10. Kang, P.S. \& Manyonge L.M. (2014). Exploration of lean principals in higher educational institutes - based on degree of implementation and indigence. International Journal of Scientific \& Engineering Research, 5(2), 831-838.

11. Jahan, M., \& Doggett, M. A. (2015). A study on the students' perceptions of the applicability of lean principles at universities. Proceedings from $122^{\text {nd }}$ ASEE Annual Conference \& Exposition: Making Value for Society, June 14-17, Seattle, WA

12. Pedersen, K.L., Ziegler, M.J. \& Holt, L.D. (2015). Striving for operational excellence in higher education: A case study implementing lean for distance learning. Quality Approaches in Higher Education, 6(2), 4148.

13. Bargerstock, A.S. \& Richards, S.R. (2015). Case study: application of DMAIC to academic assessment in higher education. Quality Approaches in Higher Education, 6(2), 31-40.

14. Svensson, C., Antony, J., Ba-Essa, M., Bakhsh, M. \& Albliwi, S. (2015). A lean six sigma program in higher education. International Journal of Quality and Reliability Management, 32(9), 951-969, doi: 10.1108/IJQRM-09-2014-0141.

15. Waterbury, T. (2015). Learning from the pioneers: A multiple-case analysis of implementing Lean in higher education. International Journal of Quality \& Reliability Management, 32(9), 934-950. https://doi.org/10.1108/IJQRM-08-2014-0125

16. Reilly, S., Healy, J., Murphy, T., \& O'Dubhghaill, R. (2017). A continuous improvement journey in the higher education sector: A case study of a university in Ireland, 7-15. Proceedings of the 4th International Conference on Lean Six Sigma for Higher Education, Ireland, May 25-26.

17. Balzer, W.K., Krehbiel, T.C., \& Francis, D.E. (ND). Lean in higher education: review of literature. Retrieved from https://the-lmj.com/2017/03/lean-applications-in-higher-education-part-one/ and https://the-lmj.com/2017/03/lean-applications-in-higher-education-part-two/

18. Dennis, P. (2015). Lean Production Simplified. Boca Raton, FL: CRC Press 